Case Report

\title{
Outbreak of hypernatremia, hyperthermia \& azotemia during summer months among neonates admitted to tertiary care NICU and their immediate outcome
}

\author{
Manoj D', Manu C. ${ }^{2}$, Guruprasad ${ }^{3}$ \\ ${ }^{1}$ Dr. Manoj Donthamsetty, Junior Resident, ${ }^{2}$ Dr. Manu C, Junior Resident, ${ }^{3}$ Dr. Guruprasad, Professor, Head of the \\ Department; all authors are affiliated with Department of Neonatology, Bapuji Child Health Institute and Research, \\ Centre, Davangere, Karnataka 577004, India.
}

Corresponding Authors: Dr. Manu C, Junior Resident, \#12,J.J.M.M.C Boys Hostel, Davanagere, Karnataka 577004, India, E-Mail: dr.manuhassan@gmail.com

\begin{abstract}
Background: Dehydration and hypernatremia amongst exclusively breast fed neonates due to inadequate breast feeding or due to less feeding is a potentially devastating condition, and its incidence rate increases during hot environment especially during summer months. We conducted this study to identify possible etiology behind dehydration and hypernatremia among healthy newborn. Methods: Hospital case records of 40 neonates admitted to the NICU in Bapuji Child Health Institute and Research Centre, Davangere during summer months (March -May) 2017 were retrospectively analysed. Case records were reviewed and data collected on parity of the mother, feeding practices,symptoms and signs at presentation, external environment temperature during the week prior to admission, biochemical changes and outcome. Results: During March-May 2017, there were 620 admissions in NICU. Amongst 620 cases, clinical profile, signs and symptoms, biochemical profile and outcome of 40 cases of hyperthermia were studied. $95 \%$ cases had significant weight loss (13-15\%), 100\% cases had hyperthermia (mean temp 99.3-101 F), 88\% cases had hypernatremia (mean Na+ $155-$ 185), $75 \%$ cases had azotemia (mean urea 96.73), creatinine(mean 1.5 ). 95\% cases were successfully treated according to NICU protocol and discharged within a short period but succumbed.Conclusion: Dehydration and hypernatremia is preventable and treatable condition. All the mothers need to taught correct feeding method like proper position and attachment of feeding. Signs of dehydration must be explained to mother as well as close relatives. Follow up visits should be ensured and check for weight is must. Not to encourage mother to give any other feed apart from exclusive breast feeding for first 6 months and even during summer months.
\end{abstract}

Keywords: Dehydration, Exclusive breast feeding, Hypernatremia

\section{Introduction}

Exclusive breastfeeding for the first 6 months of life is recommended by the World Health Organization to optimize the growth and development of the infants [1]. Breast milk in addition to nutrients provides various immunological factors that help to reduce the diarrheal and respiratory illness in children [2].

Breast feeding is an instinct behaviour and many mother-baby dyads accomplish it successfully [3]. However, some babies may not receive enough milk from their mothers due to various reasons. If breastfeeding is inadequate, then malnutrition and

Manuscript received: $10^{\text {th }}$ August 2018

Reviewed: $20^{\text {th }}$ August 2018

Author Corrected: $25^{\text {th }}$ August 2018

Accepted for Publication: $29^{\text {th }}$ August 2018 hypernatremia dehydration canoccur in the baby [4]. Moritz et al. have termed this condition as "breastfeeding associated hypernatremia" (BFAH) [5]. An increase in the incidence of BFAH in otherwise healthy neonates has been observed in the past few years [5-8]. The clinical features and complications seen in these babies have been reported in various studies [9]. It has been found that daily weighing of the babies helps in the early recognition of this illness $[10,11]$.

Dehydration in exclusively breast-fed baby needs to be identified and treated as early as possible, so that mothers are not discouraged from breastfeeding. Dehydration can be life threatening, it may cause severe renal impairment and sometimes causes acute kidney 


\section{Case Report}

injury, which can lead to morbidity and mortality. Hypernatremic dehydration is a lethal condition and is associated with cerebral edema, intracranial hemorrhage hydrocephalus. As extracellular water level decreases there is increase in serum sodium. Hypernatremia was thought to be unusual in breast fed babies [12]. Since 1990 s, there has been an increase in the number of breastfed infants reported to have hypernatremia and hypernatremia dehydration. The condition carries an acute morbidity and mortality [13].

$\mathrm{Na}$ content of colostrum in first 5 days is $22 \mathrm{mmol} / \mathrm{l}$ and transitional milk from day 5 to day 10 is $13 \mathrm{mmol} / \mathrm{l}$ and of mature milk after 15 days is $7 \mathrm{mmol} / 1[14,15]$. Inadequate milk production due to insufficient lactation may lead to dehydration. This condition gets aggravated during hot and humid atmosphere. During summer months baby losses more water due to large surface area, and these babies only receives breast milk, which may not be sufficient for baby's requirement may lead to dehydration and presents with fever, convulsions, prerenal-acute kidney injury. So, we conducted this study to identify possible etiology of dehydration in exclusively breast feed newborns during summer months.

\section{Aims and Objectives}

To study the clinical, biochemical profile and outcome of neonates who presented with hyperthermia and heat related illness

\section{Materials and Methods}

Hospital case records of 40 neonates admitted to the NICU in Bapuji Child Health Institute and Research Centre, Davangere during summer months (march may) 2017 were retrospectively analyzed. Case records were reviewed and data collected on parity of the mother, feeding practices, symptoms and signs at presentation, external environment temperature during the week prior to admission, biochemical changes and outcome.

\section{Result}

During March-May 2017, there were 620 admissions in NICU. Amongst 620 cases, clinical profile, signs and symptoms, biochemical profile and outcome of 40 cases of hyperthermia were studied.

Table-1: Anthropometry and biochemical values at admission.

\begin{tabular}{|c|c|c|c|c|c|}
\hline & N & Minimum & Maximum & Mean & Std. Deviation \\
\hline Age (Days) & 40 & 3 & 28 & 7.22 & 6.322 \\
\hline Gravida & 40 & 1 & 2 & 1.40 & .496 \\
\hline Birth weight (kg) & 40 & 1.8000 & 4.0000 & 2.728750 & .5138951 \\
\hline Admission weight & 40 & 1.4000 & 3.6000 & 2.231250 & .4871013 \\
\hline External temp & 40 & 99.6 & 103.0 & 100.380 & .9693 \\
\hline $\mathrm{Na}$ & 40 & 145 & 210 & 159.20 & 15.841 \\
\hline urea & 40 & 43 & 188 & 96.73 & 39.092 \\
\hline Creatinine & 40 & 1.0000 & 2.8000 & 1.567500 & .3931383 \\
\hline
\end{tabular}

Abnormalities noted were as follows: $95 \%$ cases had significant weight loss (13-15\%), 100\% cases had hyperthermia (mean temp 99.3-101 F), 88\% cases had hypernatremia (mean Na+155-185), 75\% cases had azotemia (mean urea 96.73), creatinine(mean 1.5). 95\% cases were successfully treated according to NICU protocol and discharged within a short period but succumbed Table 1

Table- 2: Chief complaints at admission.

\begin{tabular}{|c|c|c|}
\hline Complaints & Frequency & Percentage \\
\hline Poor feeding, excessive cry & 20 & 50.0 \\
\hline Poor feeding, excessive cry, yellowish discolouration of eyes & 20 & 50.0 \\
\hline Total & 40 & 100.0 \\
\hline
\end{tabular}

The chief presenting complaints were poor feeding,excessive irritability and yellowish discoloration of eyes. Table 2 
Case Report

Table-3: Signs at Presentation.

\begin{tabular}{|c|c|c|}
\hline Signs & Frequency & Percentage \\
\hline Tachypnea & 33 & 82.5 \\
\hline lethargy & 4 & 7.5 \\
\hline convulsions & 3 & 10.0 \\
\hline Total & $\mathbf{4 0}$ & $\mathbf{1 0 0}$ \\
\hline
\end{tabular}

The signs noted at the time of admission to the hospital were: fever, tachypnea, convulsions and lethargy Table Of the 40 cases admitted to the NICU, assisted ventilation was required in 17 cases. Table 4

Table-4: Ventilatory Assistance.

\begin{tabular}{|c|c|c|}
\hline Ventilator Support & Frequency & Percentage \\
\hline Not required & 33 & 82.5 \\
\hline Required & 7 & 17.5 \\
\hline Total & $\mathbf{4 0}$ & $\mathbf{1 0 0 . 0}$ \\
\hline
\end{tabular}

Table-5: Prognosis.

\begin{tabular}{|c|c|c|}
\hline Outcome & Frequency & Percentage \\
\hline Unfavourable & 2 & 5.0 \\
\hline Favourable & 38 & 95.0 \\
\hline Total & $\mathbf{4 0}$ & $\mathbf{1 0 0 . 0}$ \\
\hline
\end{tabular}

Of the total cases admitted, outcome was favorable in $95 \%$ of the cases and the rest succumbed to illness the major cause being sepsis. Table 5

\section{Discussion}

The dry \& warm condition in Central Karnataka is conducive for heat waves. Summer of 2017 was one of the hottest summer on record in India. Summer months of March, April and May experienced a record setting heat wave with temperature reaching as high as $46.8 \mathrm{C}$. This heat wave during the summer months explains the most cases reporting during these months followed by June.

A study from north India also showed that $36.8 \%$ of newborns were hyper thermic during summer months. A significant proportion of babies are likely to suffer from hyperthermia especially in warm climates because a strong correlation between room air, environmental temperature and neonatal temperature was observed [16].

In present study, slightly higher number of males correlates with the slightly adverse sex ratio in favour of males. The gender difference between the neonates is not statistically significant. Most neonates were affected during the first 3 days of life and mean age of the neonates affected was 7 days. This can be attributed not only to high environmental temperature but canalso be attributed to poorly established feeding pattern and physiological phenomenon of fluid loss during the first 3 days of life after delivery. Most neonates (33, 82.5\%) were of normal birth weight and few $(7,17.5 \%)$ having low birth weight $(1.8-2.5 \mathrm{kgs})$. No neonates from the very low birth weight category $(<1.5 \mathrm{Kg})$ developed hyperthermia. This can be explained by the fact that all preterm / very low birth weight neonates were admitted in NICU which is a thermo-control unit. Most neonates (30, 75\%) were delivered normally and remaining $(10,25 \%)$ through Caes are an section delivery.

Inadequate feeding was found in all the neonates; supporting the fact that adequacy of feeding is directly linked with dehydration and poses an additional risk of hyperthermia to neonates. In the present study, the duration of stay in the hospital ranged from 3-7days.

Babies were brought with complaints of not feeding well, excessive crying, lethargy, high body temperature ranging between $99-103^{\circ} \mathrm{F}$, reduced urine output and severe dehydration. Investigations done revealed Hypernatraemia and deranged renal functions. All the neonates were managed symptomatically but 7 babies required Mechanical ventilation of which 5 had successful outcome and 2 succumbed. 
Case Report

The relationship of dehydration with hyperthermia is bidirectional. Dehydration is not only the cause of hyperthermia but also the effect of hyperthermia. This vicious relationship is aggravated by inadequacy of feeding. The presence of various signs supports the sequential events during worsening of hyperthermia, with refusal to feed and dehydration appearing first, followed by irritability and lethargy.

Breast feeding is considered to be the best and safest way to feed neonates. Human milk is low in sodium, which mitigates against the possible development of hypernatremia in breast fed neonates [17].

Compared with cow's milk mature human milk contains considerably less sodium, potassium and chloride. Higher level of sodium in breast milk is associated with lactation failure, and a reduction in feeding frequency is associated with marked rise in milk sodium concentration. 6 This might be related to reduce breast milk production, which could in turn be secondary to maternal factors or neonatal factors. Insufficient milk production is the most important factor in the induction of hypernatremia. Low level of maternal knowledge in lactation, cesarean section and failure of early postnatal follow up was associated with the neonatal dehydration. Decreased urine and stool frequency might be considered as a warning for failure of lactation [18].

Hypernatremia is lethal condition leads to cerebral edema, intracranial hemorrhage, seizures, disseminated intravascular coagulation and finally death. Hypernatremic dehydration in exclusively breast-fed neonates is preventable. Primipara should be given appropriate counseling and support for successful initiation of breastfeeding and maintenance of lactation [19]. The health care provider should be aware of this potentially serious complication of exclusive breastfeeding and recognize neonates at risk for this potentially lethal condition. In conclusion it is important to be aware that hypernatremic dehydration can occur in the neonatal period due to inadequate breastfeeding. It is therefore important to ensure adequate hydration in breastfed neonates [20]. The other causes of hypernatremia should be ruled out before attributing hypernatremia to inadequate breastfeeding.

\section{Conclusion}

Postnatal weight loss in the first week of life is physiological and benign. However following points should be kept in mind during summer months

1) Neonate continues to lose weight for a longer time
2) Environmental factors play an important role in neonatal dehydration

3) Hypernatremia is an important associated electrolyte disturbance

4) Azotemia with varying grade are seen, which is reversible with good supportive care.

Funding: Nil, Conflict of interest: None initiated, Perission from IRB: Yes

\section{References}

1. Kramer MS, Kakuma R. The optimal duration of exclusive breastfeeding: a systematic review. Adv Exp Med Biol. 2004;554:63-77.

2. Eidelman AI, Schanler RJ. Breastfeeding and the use of human milk. AAP policy statement. Pediatrics 2012; 129: e827-41.

3. Volk AA. Human breastfeeding is not automatic: Why that's so and what it means for human evolution. J Soc Evol Cult Psychol2009;3:305-14.

4. Livingstone VH, Willis CE, Abdel-Wareth LO, et al. Neonatal hypernatremic dehydration associated with breast-feeding malnutrition: a retrospective survey. CMAJ. 2000 Mar 7;162(5):647-52.

5. Moritz ML, Manole MD, Bogen DL, Ayus JC. Breastfeeding-associated hypernatremia: are we missing the diagnosis? Pediatrics. 2005 Sep;116(3):e343-7.doi: $10.1542 /$ peds.2004-2647

6. Laing IA, Wong CM. Hypernatraemia in the first few days: is the incidence rising? Arch Dis Child Fetal Neonatal Ed. 2002 Nov;87(3):F158-62.

7. Cooper WO, Atherton HD, Kahana M, Kotagal UR. Increased incidence of severe breast feeding malnutrition and hypernatremia in a metropolitanarea. Pediatrics. 1995 Nov;96(5 Pt 1):957-60.

8. Trotman H, Lord C, Barton M, Antoine M. Hypernatraemic dehydration in Jamaican breastfed neonates: a 12-year review in a baby-friendly hospital. Ann Trop Paediatr. 2004 Dec; 24(4):295-300. doi:10. $1179 / 027249304225019118$

9. Lavagno C, Camozzi P, Renzi S, et al. BreastfeedingAssociated Hypernatremia: A Systematic Review of the Literature. J Hum Lact. 2016 Feb;32(1):67-74. doi: 10. 1177/0890334415613079. Epub 2015 Nov 3. 


\section{Case Report}

10. Iyer NP, Srinivasan R, Evans K, et al. Impact of an early weighing policy on neonatal hypernatraemic dehydration and breast feeding. Arch Dis Child. 2008 Apr; 93(4):297-9. Epub 2007 May 2.

11. Konetzny G, Bucher HU, Arlettaz R. Prevention of hypernatraemic dehydration in breastfed newborn infants by daily weighing. Eur J Pediatr. 2009 Jul; 168 (7): 815-8. doi: 10.1007/s00431-008-0841-8. Epub 2008 Sep 26.

12. Konetzny G, Bucher HU, Arlettaz R. Prevention of hypernatraemic dehydration in breastfed newborn infants by daily weighing. Eur J Pediatr. 2009 Jul;168 (7): 815-8. doi: 10.1007/s00431-008-0841-8. Epub 2008 Sep 26.

13. Mujawar NS, Jaiswal AN. Hypernatremia in the Neonate: Neonatal Hypernatremia and Hypernatremic Dehydration in Neonates Receiving Exclusive Breastfeeding. Indian J Crit Care Med. 2017 Jan; 21 (1):3033. doi: 10.4103/0972-5229.198323.

14. Koo WW, Gupta JM. Breast milk sodium. Arch Dis Child. 1982;57:500-2.
15. Laing IA. Hypernatremic dehydration in newborn infants.Acta Pharmacol Sin.2002;23(Supplement):48-51

16. Kumar R,Aggarwal AK.Body temperatures of home delivered newborns in north India.Trop Doct. 1998 Jul; 28(3):134-6. doi:10.1177/004947559802800304

17. Boskabadi H, Maamouri G, Ebrahimi M, GhayourMobarhan M, Esmaeily H, Sahebkar A. et al. Neonatal hypernatremia and dehydration in infants receiving inadequate breast feeding. Asia Pac J Clin Nutr. 2010; 19 (3):301-7.

18. Yaseen H, Salem M, Darwich M. Clinical presentation of hypernatremic dehydration in exclusively breast-fed neonates. Indian J Pediatr. 2004 Dec; 71 (12):1059-62.

19. Krishnamurthy S, Debnath S, Gupta P. Breast feeding- associated hypernatremic dehydration: A preventable tragedy in newborn infants. J Case Reports. 2011 Mar;1(1):1-5.

20. Bhat SR, Lewis P, David A, Liza SM. Dehydration and hypernatremia in breast-fed term healthy neonates. Indian J Pediatr. 2006 Jan;73(1):39-41.

\section{How to cite this article?}

Manoj D, Manu C, Guruprasad. Outbreak of hypernatremia, hyperthermia \& azotemia during summer months among neonates admitted to tertiary care NICU and their immediate outcome. Int J Pediatr Res.2018;5(9):446-450. doi:10.17511/ijpr.2018.i09.03. 